Research Article

\title{
Complex Network of Scientific Talent Migration in Discrete Dynamics from 2001 to 2013
}

\author{
Yinqiu Wang $\mathbb{D}^{1},{ }^{1}$ Hui Luo, ${ }^{2}$ and Yunyan Shi ${ }^{1}$ \\ ${ }^{1}$ National Academy of Innovation Strategy, Beijing 100863, China \\ ${ }^{2}$ China Centre for International Science and Technology Exchange, Beijing 100863, China \\ Correspondence should be addressed to Yinqiu Wang; wh6509@yahoo.com
}

Received 18 March 2020; Accepted 19 June 2020; Published 16 July 2020

Academic Editor: Florentino Borondo

Copyright ( 2020 Yinqiu Wang et al. This is an open access article distributed under the Creative Commons Attribution License, which permits unrestricted use, distribution, and reproduction in any medium, provided the original work is properly cited.

Scientific talents can make great contributions, including scientific breakthrough innovations and discoveries, and coordinate and guide the actions of many others, propelling the scientific knowledge frontier. We investigate international scientific talent migration from 2001 to 2013 with the quantitative method. The relationship between complex network and international talent migration is introduced. Considering most of talents migrate between some countries with good economy and innovation, the migration network including 37 countries is analysed. The countries are noted by nodes of the migration network, and the migratory flow of talents from one country to another country is viewed as the directed weight edge between the corresponding nodes. The discrete dynamics of talent migration under complex network is proposed. The unknown parameters of the proposed model are identified. The overall situation and time evolution of international talent migration from 2001 to 2013 are given from the discussion on the indicators of complex network. Furthermore, we study the talent migration flows in the view of obstacle factors. It is found that the great majority of talents migrate between developed countries and emerging economies from 2001 to 2013, and this phenomenon becomes more significant. The USA has attracted a great number of talents all over the world, and the country is also the ideal destination for talents who want to live or work in another country for more job opportunities, attractive payment, and better innovation environment. China and India begin to attract talents. Talents emigrate from more and more original countries. It becomes more convenient for talents to immigrate to other countries. The effectiveness of obstructs to migration has become weakening. For immigrating to a certain country, the obstacles have a relationship with the country's innovation.

\section{Introduction}

With the rapid growth of knowledge economy and economic globalization, the number of scientific talents working or studying in foreign countries becomes increasing. As mentioned by Beechler and Woodward [1], scientific talents are a kind of professional class who have strong desire to move. They are used to immigrating to other countries, which can give them secure environment, good job opportunities, attractive remuneration, sophisticated laboratory conditions, or other benefits. In another way, the frequent international migration of scientific talents also leads to new scientific communication, cooperative research, and chances for industrial development [2]. Moreover, scientific talents are also a kind of key factors for developing science and innovation [3]. The countries attracting a great number of scientific talents will be at the top of science and technology in the world. Hence, many countries are actively engaged in the global talent competition and introduce substantive policies to attract talents, intensifying the degree of international talent migration [4]. Therefore, the phenomenon of international talent migration is unavoidable. Then, investigation of talent migration and its causes is very important to attract more talents from other countries. It follows that more scholarly and policy attention has been paid to this topic.

The international migration of scientific talents is complex and multidimensional. The initial study of this topic just focused on the phenomenon of brain drain or brain gain, for example, in [3,5-8]. The work [3] reviewed 
analytical and policy issues related to the international migration of talented individuals, examining the main types of talent who moved internationally, their specific traits, characteristics, and the implications of migration for original and host countries and for global development. In [6], the authors examined how Chinese- and Indian-born engineers were accelerating the development of the information technology industries in their home countries, initially by tapping the low-cost skill in their home countries and over time by contributing to highly localized processes of entrepreneurial experimentation and upgrading, while maintaining close tied to the technology and markets in Silicon Valley. According to [7], more and more the migration pattern changed from a blue-collar migration of low qualified workers to a white-collar migration of highly skilled professionals, and there was a substantial brain drain from 1991 to 2000. In [8], the authors analysed the importance of foreign talents for host countries, considered the determinants of international talent flows at the individual and firm levels, and sketched some important implications.

However, in these above results, only permanent migration was discussed through case analysis in empirical method. Furthermore, these results might not give an overall situation and might not be very convincing. Considering these imperfections, a lot of scholars and policy makers try to analyse international talent migration and its causes with the quantitative approach.

The most general quantitative method to investigate talent migration is according to bibliometrics to tracking international scientific migration, based on an analysis of the affiliation countries of authors publishing in peer-reviewed journals. For example, in $[9,10]$, the authors declared this approach was promising, and a bibliometric study of scientific migration provided significant outcomes. As discussed by Czaika and Orazbayev [11], they found an increasing diversity of original and host countries integrated in global scientific migration and significantly lower migration frictions for internationally migratory scientists compared to nonscientist migrants with the help of a quantitative assessment of global scientific migration over the past four decades based on bibliometric data. The authors in [12] established the networked model of international talent migration, investigated the topic with complex network analysis, and identified factors to explain international talent migration flows by multiple linear regression. They said that the share of migrants in population was the major negative factor for international talent migration, and the factors of host countries were more significant than original countries. The work in [13] proposed a framework model of international top talent migration and gave two approaches to identify unknown parameters. The result could be employed to analyse the overall situation of international talent migration and predict its development. Furthermore, according to the analysis of a novel estimation procedure based on a pseudo-gravity model in [14], migration to non-OECD countries accounted for $20 \%$ of all high-skilled migration and this migration comprised relatively large numbers of individuals from low income and the least developed countries in many regions of the world. To provide an initial and exploratory contribution to the analysis of the factors driving the international migration of talents, the work in [15] adopted an empirical gravity model to describe and analyse new aggregate, bilateral data on international scientist migration. In [16], determinants of international scientific migratory inflows were quantified from multiple sources using panel-data analysis techniques. In [17], the authors estimated international migration models for OECD countries based on a dual approach: using conventional econometric approaches such as panel-data regression and network-based regression techniques such as multivariate regression quadratic assignment procedures.

Moreover, complex network is a kind of helpful tools to study some social problems similar to international migration of talents, such as population migration and international trade. In [18], the international migration was noted as a weighted-directed graph where nodes were countries and links accounted for the stock of migrants originated in a given country and living in another country at a given point in time. In [19], the proposed novel human migration model managed to construct the $k$-clique overlapping community structuring the common statistical features observed from distinct real social network and achieved a good trade-off between complexity and reality. In [20], a network model of human migration with migration cost including movement/translocation and training is introduced. The proposed model not only permitted migration of a class across regions but also allowed for class transformations within a region or across regions.

In our opinion, the biggest challenge of studying international migration of scientific talents is to obtain confidential data suitable for evaluation and measurement of its characteristics and impact. Furthermore, the difficulty becomes more serious due to existing complex circulation immigration and tracking trajectories of talents across borders. According to immigration statistics of population and working people, traditional method can just portray the migration flow of top talents, and the collected data is incomplete in some cases.

With studies extend, many questions about international talent mobility are emerging and hinged on the policy agenda of governments. For example, what is the relationship between countries in talent migration? What is the evolvement of international talent migration in recent years? To what extent is the effectiveness of obstructs in the international scientific migration of talents? The answers to these questions are very important for governments to initiate policies in order to attract talents all over the world, so that they must be explored with great conviction.

To deal with these questions, in this paper, international scientific talent migration is investigated in convincing way with the help of quantitative analysis. Talent migration is viewed as complex network, and the stock of talents in each country is given by a discrete dynamics. In addition, based on the existing data of talent migration from bibliometrics, the unknown parameters of the talent migration networked model are identified. Moreover, the evolution of talent migration is discussed under the proposed model. Finally, we assume the pattern of talent migration in the absence of obstacles and study the effect of obstacles in talent migration. 
The remainder of the paper is structured as follows. Section 2 describes the data source and the normalized data processing. Section 3 describes the relationship between talent migration and complex network with discrete dynamics and introduces the method to identify unknown parameters in the proposed discrete model. Section 4 discusses the effectiveness of obstacles in international talent migration. Finally, Section 5 concludes the paper.

\section{Data Source for Investigating Talent Migration}

Considering it is very difficult to obtain confidential data describing bilateral flows of talents between countries, especially the annual data, we focus on inventor migration as captured in patent applications. It can overcome many limitations associated with migrant stock data. The grouping of patent-inventing talents is more targeted than the wide spectrum of tertiary educated talents. In addition, inventors arguably have special economic importance, as they create knowledge, which realizes technological and industrial transformation.

Consequently, migratory data of talents employed in the paper come from "patent applicants," which are extracted from applications filed under the Patent Cooperation Treaty (PCT). In addition, the PCT data contains bilateral counts of cross-border movements of "migrant inventors" for a long time span, with an exhaustive list of "sending" and "receiving" countries.

The PCT is an international treaty administered by the World Intellectual Property Organization (WIPO), offering patent applicants an advantageous route for seeking patent protection internationally. The treaty came into force in 1978; and there were 146 PCT contracting states in 2012. The PCT filing data covers a large number of countries over a long time span (from 1978 to 2012). In 2010, around 54\% of all international patent applications went through the PCT system. By December 31, 2012, the total number of PCT applications stood at 2361455. Each PCT application includes the names of the applicant(s), agents, inventors, common representatives, and special addresses for correspondence. Given our interest in studying the migratory history of inventors, we only focus on inventors and applicant inventor records. This subgroup accounts for exactly 6112608 records. We observe both the nationality and residence information for 4928076 of the 6112608 records, a coverage rate of $80.6 \%$. Considering research significance, representativeness, and data integrity, we choose the time interval from 2000 to 2012 in the database.

The PCT patent applications contain information such as the names and addresses of the patent applicant(s) (generally, the owner), as well as the names and addresses of the inventor(s). What is unique about the PCT applications is that, in the majority of cases, they record both the residence and the nationality of the inventors. In sum, the PCT records offer good coverage of inventor nationality and residence information and represent a promising data source for migration research. More detailed and careful interpretation of International Migration of Inventors database is available in $[21]$.

\section{Complex Network of Scientific Talent Migration with Discrete Dynamics}

In this section, the dynamical discrete model of scientific talent migration is established, and the unknown parameters in the proposed model are identified. After that, we draw the topology of talent migration between countries and propose its characteristics and evolution.

3.1. Model Framework. In this section, we establish the networked model framework of international talent migration with discrete dynamics. Based on discussion of the relationship between complex network and international talent migration from original countries to host countries, talent migration is represented as a kind of complex network.

Complex network, which is noted by a topology, is an abstract representation of a group of nodes. The relationship between nodes is known as directed edges. The international migration of talents can be viewed as a kind of information transmission among nodes. It is natural and convenient to model international talent migration among countries by directed weighted topology. The authors in [22, 23] gave a more detailed and thorough interpretation of complex network and its applications.

Considering that we investigate the migration in a series of time, the symbol $k$ is used to note time. To describe migration in quantization as a directed topology, nodes are set as countries. It means that country $i$ is noted as node $i$ in the directed topology. In addition, the migratory channel from country $j$ to country $i$ is viewed as the edge $(j, i)$ from node $j$ to node $i$. Next, we define a directed path (directed migratory flow) as a sequence of successive nodes starting at node $j$ and ending at node $i$ so that successive nodes are adjacent. Moreover, in binary topology, the weight of any edge is 1 if the edge exists; otherwise, the weight is 0 .

The number of migratory talents (patent applicants) from country $j$ to country $i$ is denoted by $y_{i j}(k)$, and $y_{i i}(k)$ is the number of talents residing in country $i$ according to the PCT database at time $k$.

Since we aim to compare talent flows of different years to obtain the evolution of international talent migration, annual data $y_{i j}(k)$ should be normalized.

For normalizing the initial value $y_{i j}(k)$, the following method to get the normalization value $m_{i j}(k)$ is given by

$$
m_{i j}(k)=\frac{y_{i j}(k)}{\sum_{i=1}^{n} \sum_{j=1}^{n} y_{i j}(k)} \times 100,
$$

which follows that

$$
\sum_{i=1}^{n} \sum_{j=1}^{n} m_{i j}(k)=\sum_{i=1}^{n} \sum_{j=1}^{n} m_{i j}(l)=100,
$$

always holds at any time, where $n$ is the number of countries considered in the migration network. If there is no talent from country $j$ to country $i$ at time $k$, the edge $(j, i)$ does not exist, and $y_{i j}(k)=0, m_{i j}(k)=0$. It is straightforward to see that $m_{i j}(k)$ always keeps in the range $[0,100]$.

Note that the number of talents in country $i$ at year $k$ is just relative with the number of talents in countries having 
talents immigrating to country $i$ at year $k-1$. Moreover, it is also assumed that the number of talents of country $i$ at year $k$ is the accumulation of migratory talents from other countries immigrating to country $i$ at year $k-1$, including staying in country $i$. We have the following discrete dynamics:

$$
m_{i}(k)=\sum_{j=1}^{n} a_{i j}(k) m_{j}(k-1)=\sum_{j=1}^{n} m_{i j}(k-1),
$$

where $a_{i j}(k)$ is viewed as the joint factors to drive talents migrating from country $j$ to country $i$ at year $k$. In addition, in the networked model with discrete dynamics $(4), a_{i j}(k)$ is noted as the weight of edge $(j, i)$ to be identified next. Moreover, based on the normalization equation (1), we obtain $\sum_{i=1}^{n} m_{i}(k)=\sum_{i=1}^{n} m_{i}(k+1)$.

3.2. Parameter Identification. In the above section, the model framework is established, but the weight $a_{i j}(k)$ is still unknown. These parameters are the key coefficients to get characteristics of discrete migration network. In this section, we introduce the way to identify these unknown parameters.

Considering the number of talents in each country is normalized, we have that

$$
\sum_{i=1}^{n} m_{i}(k)=\sum_{i=1}^{n} m_{i}(k-1)=\sum_{i=1}^{n} \sum_{j=1}^{n} a_{i j}(k) m_{j}(k-1)=\sum_{i=1}^{n} \sum_{j=1}^{n} m_{i j}(k-1),
$$

always holds. Without loss of generality, for one certain node $i$, it is obvious that

$$
m_{i j}(k-1)=a_{i j}(k) m_{j}(k-1),
$$

because the talent flow coefficient from original country $j$ to host country $i$ just depends only on the factors of country $i$ and country $j$. Therefore, the unknown parameter is given by

$$
a_{i j}(k)=\frac{m_{i j}(k-1)}{m_{j}(k-1)} .
$$

It follows that the parameter $a_{i j}(k)$ reflects the proportion of talents from country $j$ to country $i$ to all talents in country $j$ at year $k-1$. And (6) is equivalent to $a_{i j}(k+1)=$ $m_{i j}(k) / m_{j}(k)$.

Moreover, to switch the dummy variables $i$ and $j$, we have

$$
\sum_{j=1}^{n} m_{j}(k) \sum_{i=1}^{n} a_{i j}(k)=\sum_{i=1}^{n} m_{i}(k) \sum_{j=1}^{n} a_{j i}(k) .
$$

Following from (4), we obtain

$$
\begin{aligned}
\sum_{i=1}^{n} m_{i}(k) \sum_{j=1}^{n} a_{j i}(k) & =\sum_{i=1}^{n} m_{i}(k), \\
\sum_{i=1}^{n} m_{i}(k) \sum_{j=1}^{n} a_{j i}(k)-\sum_{i=1}^{n} m_{i}(k) & =0, \\
\sum_{i=1}^{n} m_{i}(k)\left(\sum_{j=1}^{n} a_{j i}(k)-1\right) & =0 .
\end{aligned}
$$

It is straightforward to see $\sum_{j=1}^{n} a_{j i}(k)=1$. Noting $A(k)=\left[a_{i j}(k)\right] \in R^{n \times n}$, the column sum of $A(k)$ is 1 ; that is, $1^{\mathrm{T}} A(k)=0$ at any time.

\section{Topologies and Evolution of International Talent Migration}

In this section, the topologies of international talent migration between 37 countries, including the USA, the UK, Germany, France, Sweden, Japan, Australia, Switzerland, India, China, Brazil, Russia, Mexico, Indonesia, and South Africa and other major countries, are drawn from 2001 to 2013 according to a series of the identified matrices $A(k)$. The overall evolution of international talent migration is discussed with the help of indicators of complex network.

Based on the identified adjacent matrices $A(k)$, if the number of talents in a country is represented by the size of the corresponding node and the number of migratory talents from the original country to the host country is measured by the width of a directed edge, the network topologies of international talent migration are drawn in Figure 1.

Remark 1. Figure 1 just supports intuitive visualization of talent migratory network with qualitative analysis. The following credible results about talent migration are obtained according to evolutions of network indicators in the quantization.

Based on the proposed model with the help of some indicators of complex network, the characteristics and evolution of international talent migration can be discussed. Moreover, considering the characteristics and realities of international talent migration, the following statements about topology and complex network may be different from their general concepts.

The first and most crucial definition of complex network is degree, including in-degree and out-degree given by

$$
d_{i}^{\text {in }}(k)=\sum_{j=1}^{n} a_{i j}(k), d_{i}^{\text {out }}(k)=\sum_{j=1}^{n} a_{j i}(k),
$$

respectively. Degree represents the ability of the chosen countries pulling or pushing talents. It is obvious that outdegree is the sum of columns of $A(k)$, so that $d^{\text {out }}(k)=$ $1, \forall i, k$ always holds for any node. The evolutions of indegrees for the chosen countries from 2001 to 2013 are given in Figure 2.

From Figure 2, the in-degree of the USA is the maximum value. Germany is in the second position, and Switzerland, the UK, Japan, and other developed countries with high GDP per capita also have high values of in-degrees. The values of these countries' in-degrees are stable, and their indegrees are far from the USA. It is concluded that developed countries receive a great number of talents, and the number of talents residing in these countries is also very high, but the attraction of developed countries, except the USA, is stable continuously. The USA is still at the summit of the number of scientific talents all over the world. 


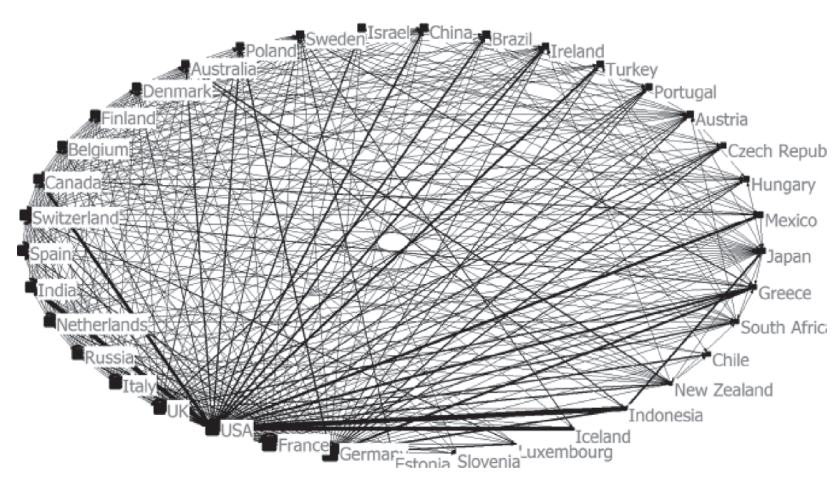

(a)

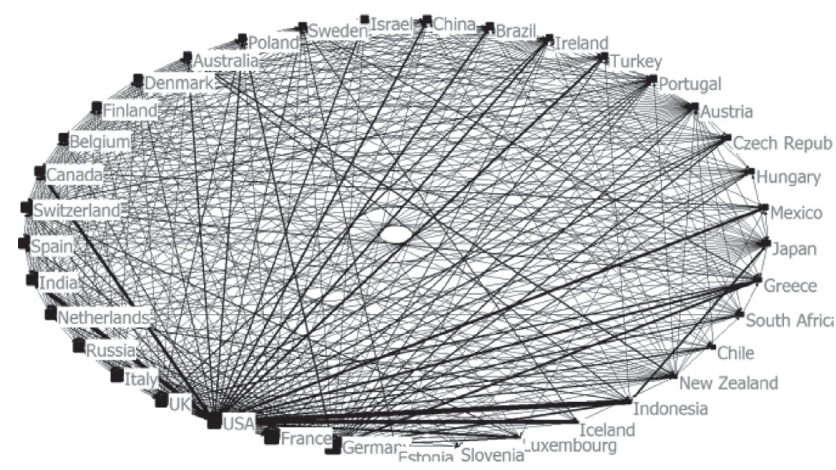

(c)

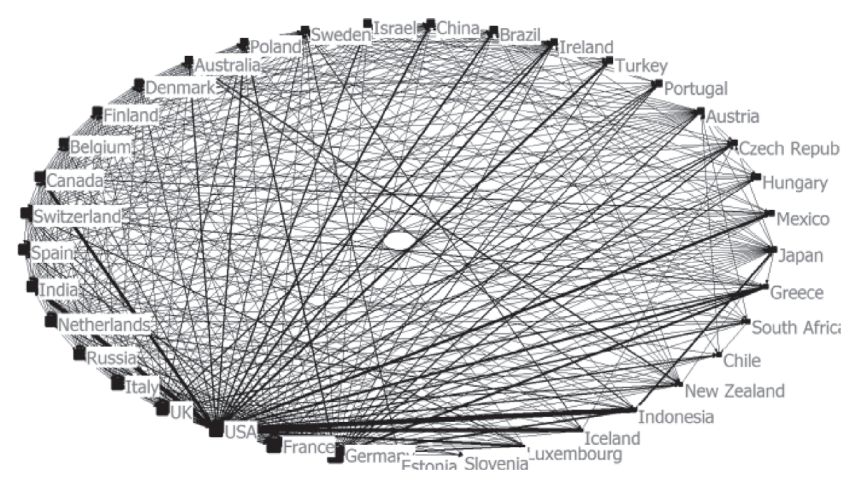

(b)

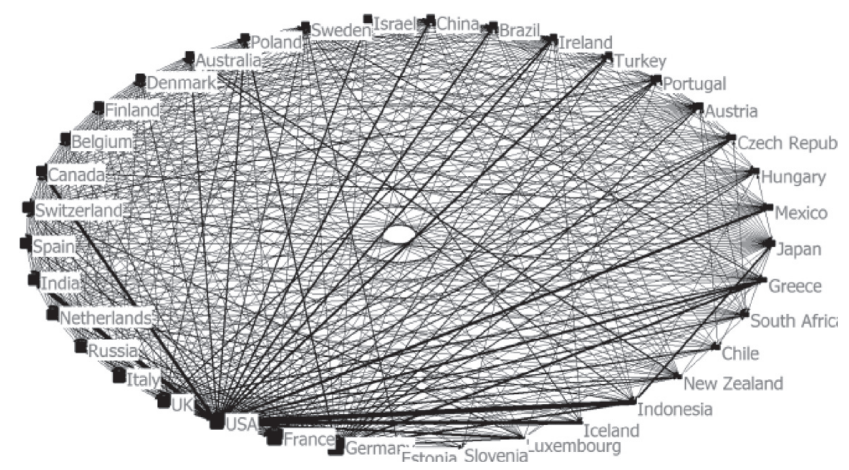

(d)

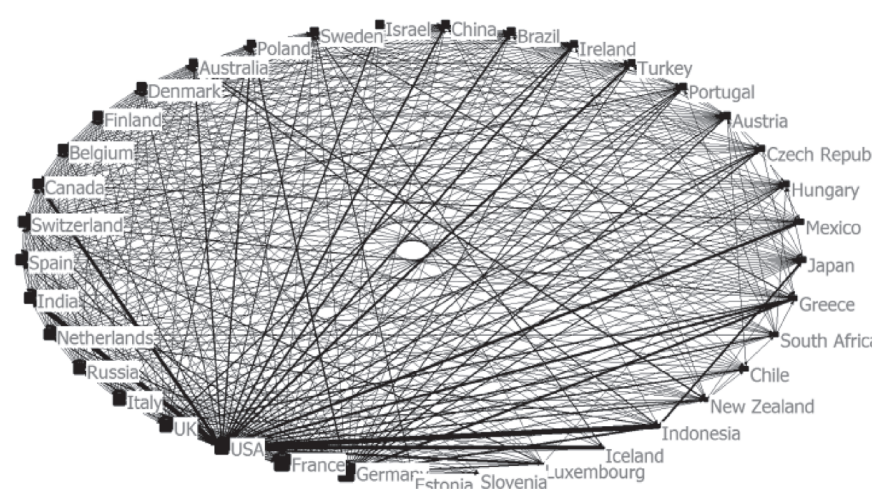

(e)

Figure 1: International migration network topologies of talents between the chosen countries in certain specific years. (a) The topology in 2001. (b) The topology in 2004. (c) The topology in 2007. (d) The topology in 2010. (e) The topology in 2013.

Another outstanding point of Figure 2 is that the indegree of China increases from 0.6222 to 1.4759 -double increasing. It means that the ability of China to attract talents is strengthened very significantly because of the development of economy and attractive policies. In addition, the indegrees of other countries, such as Indonesia and Greece, are relatively low, which means that these countries with low GDP per capita cannot attract many talents, and the number of talents residing in these countries is also very limited.

The next important indicator to study international talent migration under complex network is distance $L_{i j}$ from node $j$ to node $i$, which is defined by the minimum sum of weights of edges from $j$ to $i$ through a direct path. It is employed to measure the efficiency of information delivery in the network. Based on this idea, considering that the weights of edges represent the ability of attracting talents of host countries, the efficiency of talent migration network is defined by average distance in the following:

$$
L(k)=\frac{\sum_{i \neq j} \min \left[1 /\left(a_{c 1 j}(k)+a_{c_{2} c_{1}}(k)+\cdots+a_{c_{k} c_{k-1}}(k)+a_{i c_{k}}(k)\right)\right]}{n(n-1)},
$$

where $\left(j, c_{1}\right),\left(c_{1}, c_{2}\right), \ldots,\left(c_{k-1}, c_{k}\right),\left(c_{k}, i\right)$ is a directed path from $j$ to $i$. For talent migration, it describes the efficiency or the convenience for talents to go aboard in general. The 


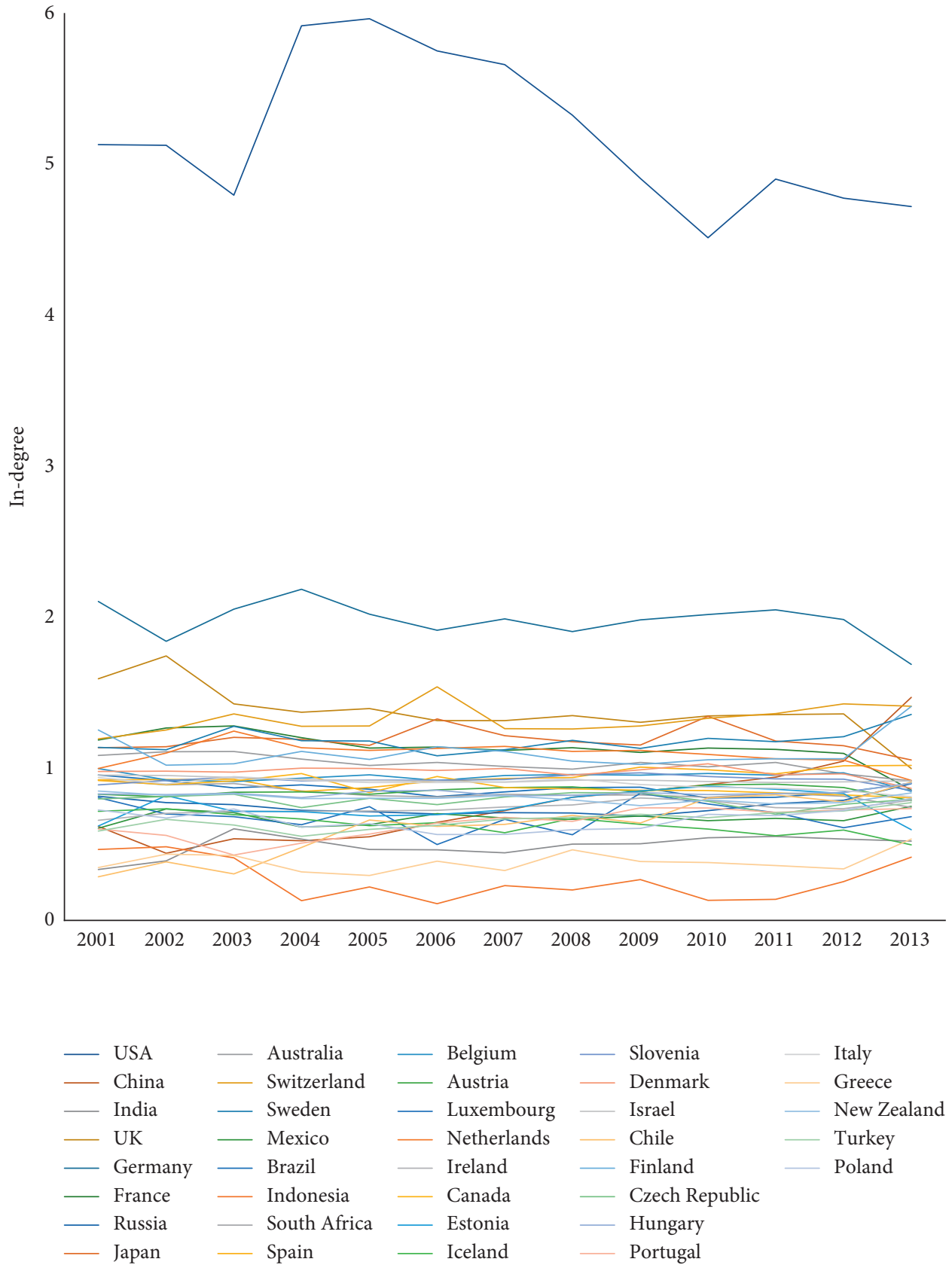

Figure 2: Evolutions of in-degrees of the chosen countries from 2001 to 2013.

smaller $L$ means that it is more convenient for talents studying or working to other countries. The average distance evolution of the talent migration network is given in Figure 3.

It is obvious from Figure 3 that the average distance becomes smaller over time, and the decreasing is significant, over $50 \%$. It means that the efficiency and convenience for talent migration were improved from 2001 to 2013. Then, we maintain that a great number of obstacles to talent migration are removed considerably, giving impetus to the transnational activities of talents for other countries.

In the theory of complex network and graph, a clustering coefficient is a measurement of the degree to which nodes in a network tend to cluster together. Clustering coefficient is a local measure. Therefore, clustering coefficient of a node under undirected network is calculated by using following formula:

$$
c_{i}=\frac{l_{i}}{d_{i}\left(d_{i}-1\right)},
$$

where $d_{i}$ is the degree of node $i$ and $l_{i}$ is the number of edges between the neighbours of node $i$.

In this paper, to investigate the network of international talent migration, we redefine this concept. For undirected binary topology, clustering coefficient is given by 


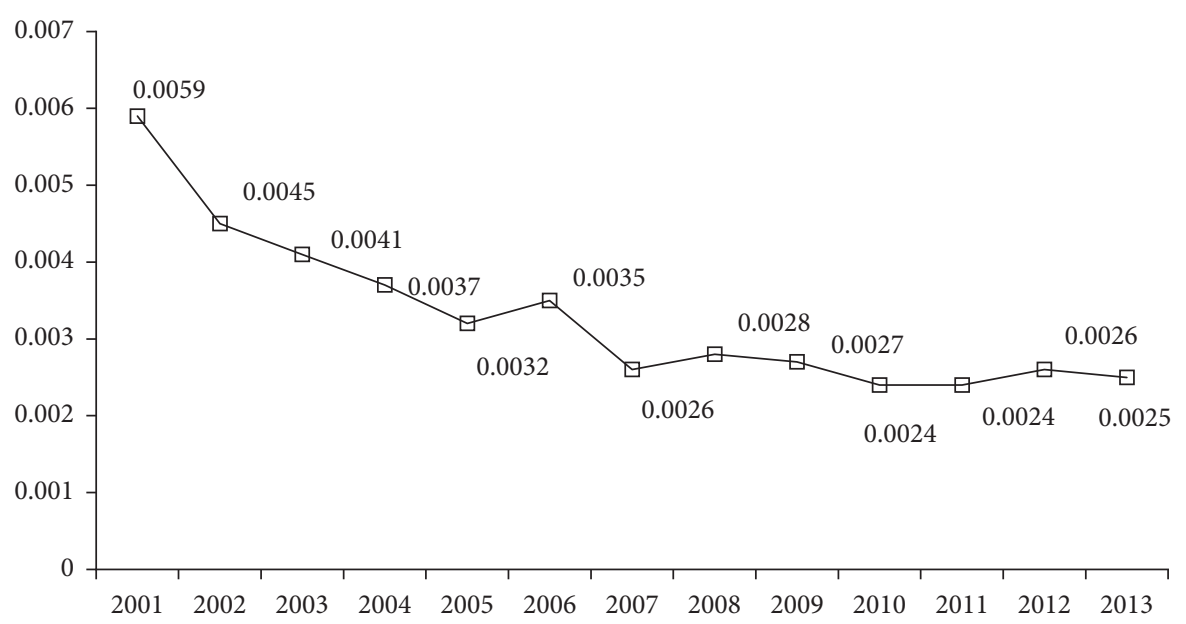

Figure 3: Evolution of average distance of international talent migration network from 2001 to 2013.

$$
c_{i}(k)=\frac{1}{l_{i}(k)},
$$

where $l_{i}$ is the number of edges connected to node $i$ under the undirected binary topology. For directed weight topology, clustering coefficient is given by

$$
c_{i}(k)=\frac{\sum_{j, k}\left[a_{i j}(k) a_{j k}(k) a_{k i}(k)\right]^{1 / 3}}{d_{i}^{\text {in }}(k)\left[d_{i}^{\text {in }}(k)-1\right]},
$$

where $a_{i j}(k), a_{j k}(k)$, and $a_{k i}(k)$ are the weights of $(j, i),(k, j)$, and $(k, i)$ at time $k$, respectively.

The clustering coefficient of the entire graph is the average clustering coefficient of the entire network, which can be employed to discuss the density of edges in average. It is given by

$$
c(k)=\frac{1}{n} \sum_{i=1}^{n} c_{i}(k) .
$$

The evolutions of clustering coefficients under directed weighted topology and undirected binary topology are calculated and drawn in Figures 4 and 5.

According to Figure 4, it is seen that the clustering coefficient under directed topology of international talent migration is close to 0.01 with volatility in range between 0.0095 and 0.0110 from 2001 to 2013 , so that it is relatively stable, which follows that the density of the weighted topologies does not change significantly. However, from Figure 5, it is obvious that the clustering coefficient under undirected binary topology is increasing from 0.8023 to 0.8325 , and the trajectory is monotonously increasing in general. It means that growing numbers of talents immigrate to other counties directly and conveniently because of the increasing clustering coefficient under undirected binary topology, which is in agreement with the result according to average distance. However, there also exists the stable density under directed weighted topology, so that most of international talent migration has been only concentrated on a small number of countries.
Moreover, to analyse which countries are critical in the talent migration, the evolutions of clustering coefficients of these countries are drawn.

According to the representation of clustering coefficient in talent migration network, it is obvious that there are the greatest numbers of immigrating talents in the USA, and the USA plays the most critical role in structure of talent migration network.

To analyse the heterogeneity of international talent migration, network structured entropy is introduced. Network is nonheterogeneous or called homogeneous if all of nodes have the same importance approximately; otherwise, the network is heterogeneous. Network structured entropy for in-degree is given by

$$
\mathcal{E}(k)=\frac{-2 \sum_{i=1}^{n} \eta_{i}\left(\operatorname{In} \eta_{i}(k)\right)-\operatorname{In}[4(n-1)]}{2 \operatorname{In} n-\operatorname{In}[4(n-1)]},
$$

where $\eta_{i}(k)=d_{i}^{\text {in }}(k) / \sum_{j=1}^{n} d_{j}^{\text {in }}(k)$. Because of $d_{i}^{\text {out }}(k)=$ $1, \forall i, k$, network structured entropy for out-degree is 1 at all times.

It is obvious that $0 \leq \varepsilon \leq 1$. In addition, if $\epsilon$ is close to 0 , the network is heterogeneous; if $\epsilon$ is close to 1, the network is nonheterogeneous. Network structured entropy can be used to estimate whether the characteristics of international talent migration depend on one country or a small group of countries.

It is seen from Figure 6 that the variation interval of entropy for in-degree is from 0.2085 to 0.1888 , far from 1 , and the monotonous decreasing of this value is obvious . According to its meaning, the international talent migration is nonhomogeneous severely. Combined with the in-degree distribution shown in Figure 2 and the clustering coefficient distribution in Figures 6 and 7, most of talents usually migrate among the countries with high GDP, and this trend is becoming more and more obvious from 2001 to 2013.

4.1. Effectiveness of Obstructs to International Talent Migration. Despite a growing international competition for talents, scientific migration is affected by the factors of 


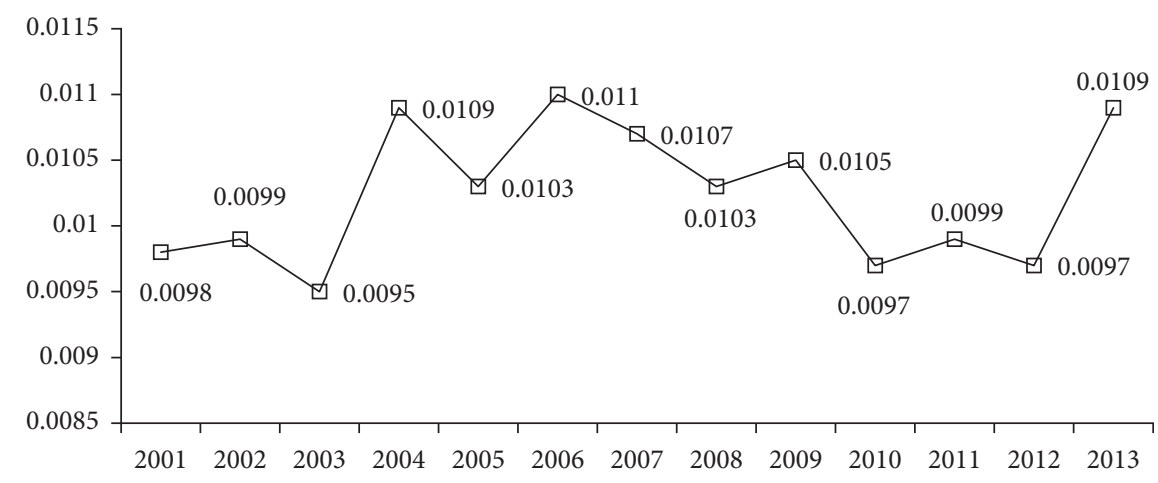

FIgURE 4: Evolution of clustering coefficient under directed weighted topology.

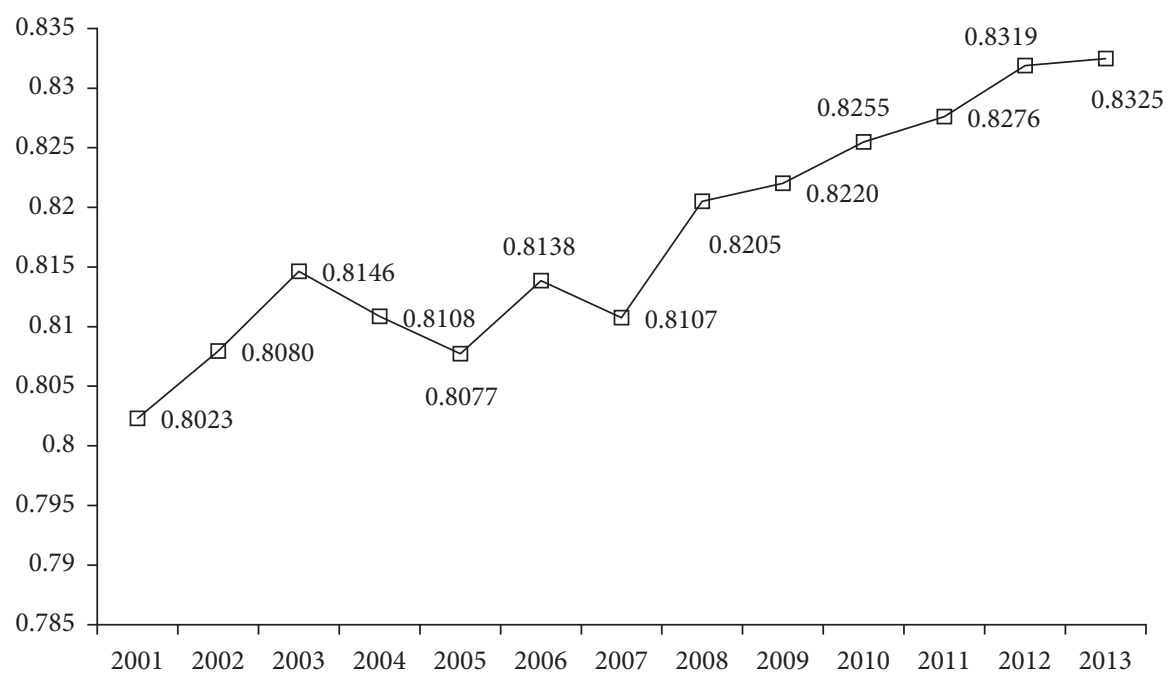

FIGURE 5: Evolution of clustering coefficient under undirected binary topology.

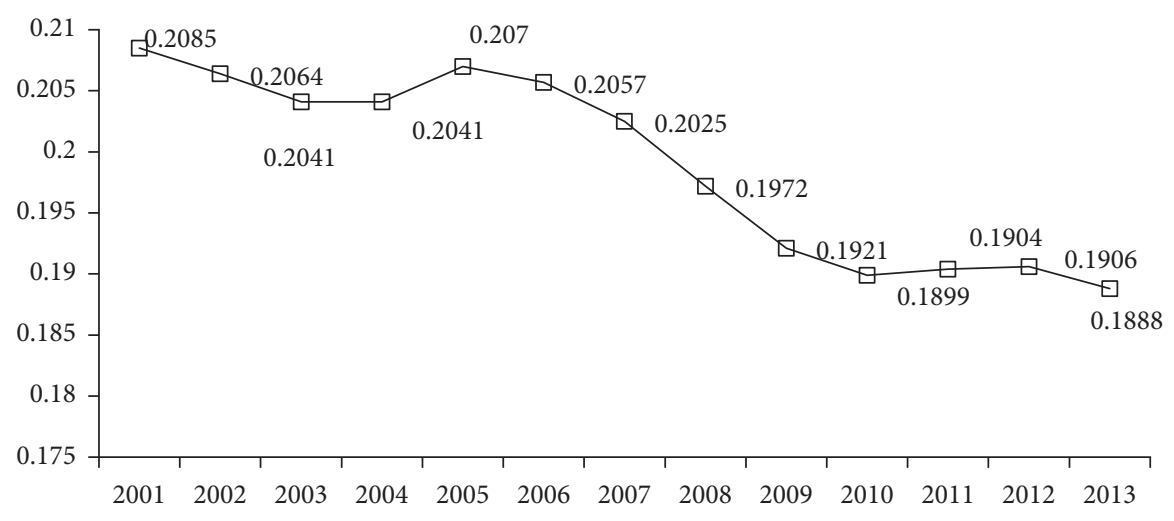

FIGURE 6: Evolution of entropy for in-degree.

obstructs certainly, as various economic, political, and professional factors continue to play a significant negative role in shaping international migration of talents. To assess the roles of obstructs, we need to construct a hypothetical counterfactual, which will answer the following question: how would migration patterns look like if there were no barriers to migration?
Following [24], we use a random-utility framework to examine what it would look like if obstructs to international talent migration were equal to zero. This is similar to the analysis made by Head and Mayer in [25], except for the fact that we analyse international talent migration instead of trade flows. 


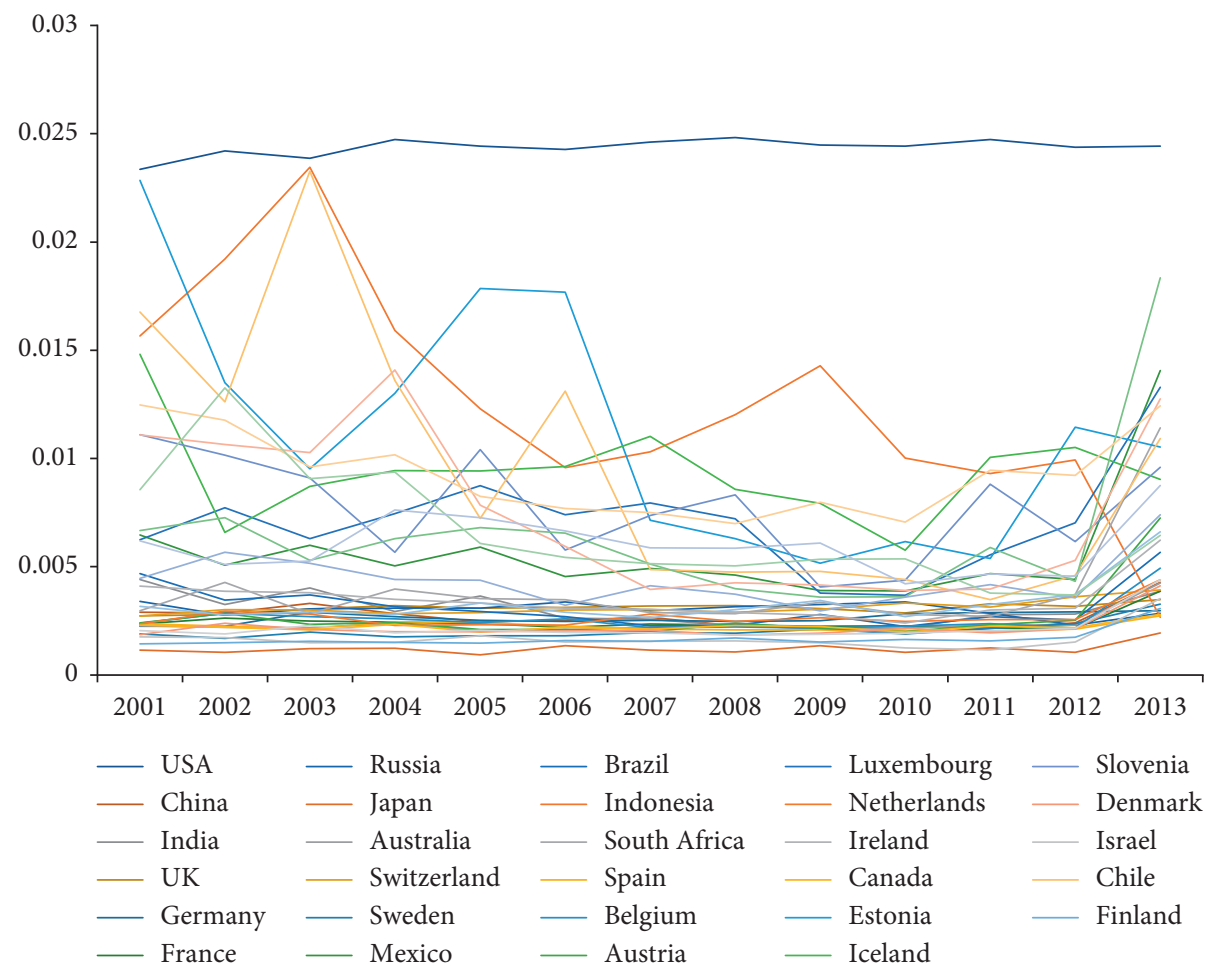

FIGURE 7: Evolutions of clustering coefficient of the chosen countries under directed weighted topology from 2001 to 2013.

Assume the individual's utility from this choice presented by the parameter $a_{i j}(k)$ identified in the above section is given by

$$
a_{i j}(k)=u_{i}(k)+c_{j}(k)+e_{i j}(k),
$$

where $u_{i}(k)$ is the attraction of host country $i$ to all original countries, $c_{j}(k)$ is the barrier factor for talents emigrating from country $j$, and $e_{i j}(k)$ is the specific random component for talent migration from country $j$ to country $i$.

To assess the role of obstructs, it is assumed that the associated items do not exist, that is assuming $c_{i j}(k)=0$. After that, compared with the results within and without the item $c_{i j}(k)$, the effect of obstructs is given.

Assuming there are no barrier factors, $a_{i j}(k)=u_{i}(k)$ holds. Hence, it follows from (3) that the number of talents in country $i$ at time $k+1$ becomes

$$
m_{i}(k+1)=\sum_{j=1}^{n} u_{i}(k) m_{j}(k)=u_{i}(k) \sum_{j=1}^{n} m_{j}(k) .
$$

Considering $\sum_{i=1}^{n} m_{i}(k)=\sum_{i=1}^{n} m_{i}(k+1)$ with normalization equation (1), we have

$$
u_{i}(k)=\frac{m_{i}(k+1)}{\sum_{j=1}^{n} m_{j}(k)}=\frac{m_{i}(k+1)}{\sum_{j=1}^{n} m_{j}(k+1)} .
$$

An intuitive interpretation of the above equation is, in the absence of obstructs, the proportion of migratory talents emigrating from origin $j$ and immigrating to destination $i$; that is, $a_{i j}(k)$ would be equal to the share of the number of talents residing in destination $i$ in the total amount of talents all over the world at the same time. Next, we denote

$$
f_{i}(k)=\frac{u_{i}(k)}{\sum_{j=1}^{n} a_{i j}(k) / n}
$$

to represent the effectiveness of obstructs. This value can represent the difficulty of talents immigrating to country $i$. For most cases, $f_{i}(k)$ is larger than 1 in reality, but $f_{i}(k) \leq 1$ may also exist. The reason of $f_{i}(k) \leq 1$ can be explained as the barrier factor $c_{j}(k)$ does not play a blocking role but encourages people to emigrate from country $j$.

The average $f_{i}(k)$ of all countries from 2001 to 2013 and its evolution are calculated and drawn in Figure 8.

Figure 8 reports that there is a decrease of average $f_{i}(k)$ from 2001 to 2013, which means that the effectiveness of obstacles is reducing during the same time.

However, through the deep analysis, we find that the obstacles for different countries are different. To show the difference, we plot the evolution of average $f_{i}(k)$ from 2001 to 2013 for each country by the average number of residing talents $y_{i}(k)$ also counting by the PCT in Figure 9. The $x$-axis of Figure 9 is chosen as the logarithm (base 10) of $y_{i}(k)$ to make the result clear.

With the number of residing talents increasing, the difficulty for talents immigrating to host countries is reducing in general, but it also maintains that after a certain value of the number of residing talents, the difficulty increases slightly. It is believed that the number of residing talents has a positive relationship with innovation ability, so 


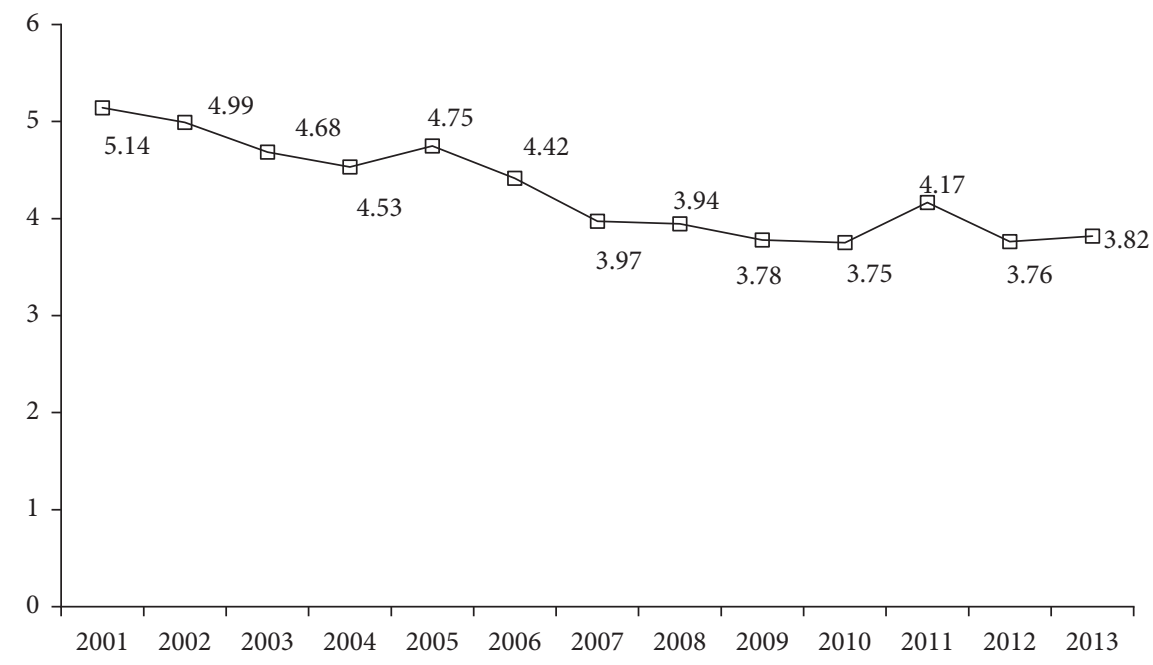

FIgURE 8: Evolution of average $f_{i}(k)$ for all countries from 2001 to 2013.

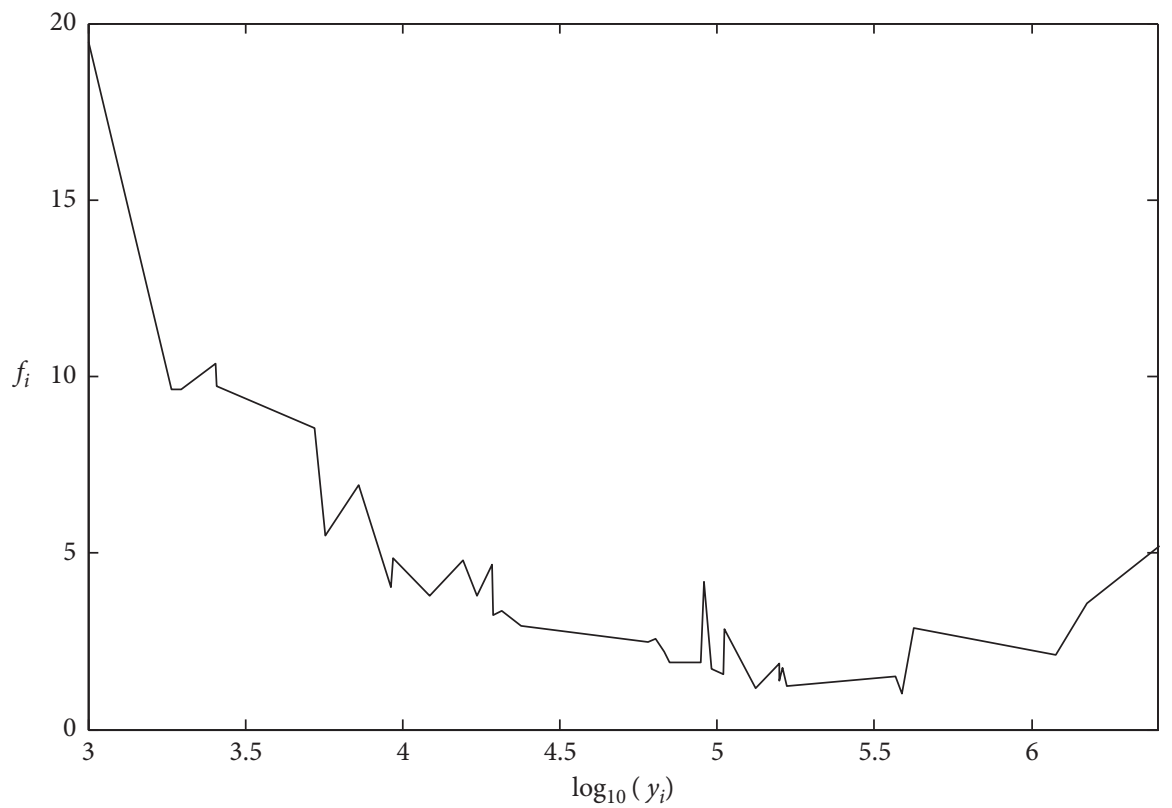

Figure 9: Evolution of average $f_{i}(k)$ by the number of residing talents from 2001 to 2013.

that countries with high innovative capabilities have attracted talents in the world, and talents have the strong will to immigrate to these countries. Nevertheless, the countries having the largest amount of talents, such as the USA, may restrict entry for normal talents because of enough talents, and these countries just welcome top ones.

For investigating the obstruct effectiveness of some typical countries, including the USA, China, the UK, Germany, Australia, and India, the time evolutions of $f_{i}(k)$ of these countries are drawn in Figure 10.

Figure 10 shows the largest value of $f_{i}(k)$ is for the USA, the most innovative countries, also having the largest amount of talents. It is analysed that it is not easy for foreign talents to study or work in the USA. As mentioned earlier, the reason may be that there are enough normal talents, and most of talents want to go to the USA for better job opportunities, attractive remuneration, or sophisticated laboratory conditions. There is similar decreasing of $f_{i}(k)$ for China and India, emerging economies. The reason is that talents immigrate to the two countries more and more conveniently. On the one hand, China and India need an increasing number of talents for innovation and development; on the other hand, the talents have chosen them as better destinations because of the good working and living conditions that the countries support. For developed countries in west Europe and Oceania, the values of $f_{i}(k)$ are stable between 2.5 and 3.5, and the range of these numerical variations is small because the attraction of these countries is not very high. 


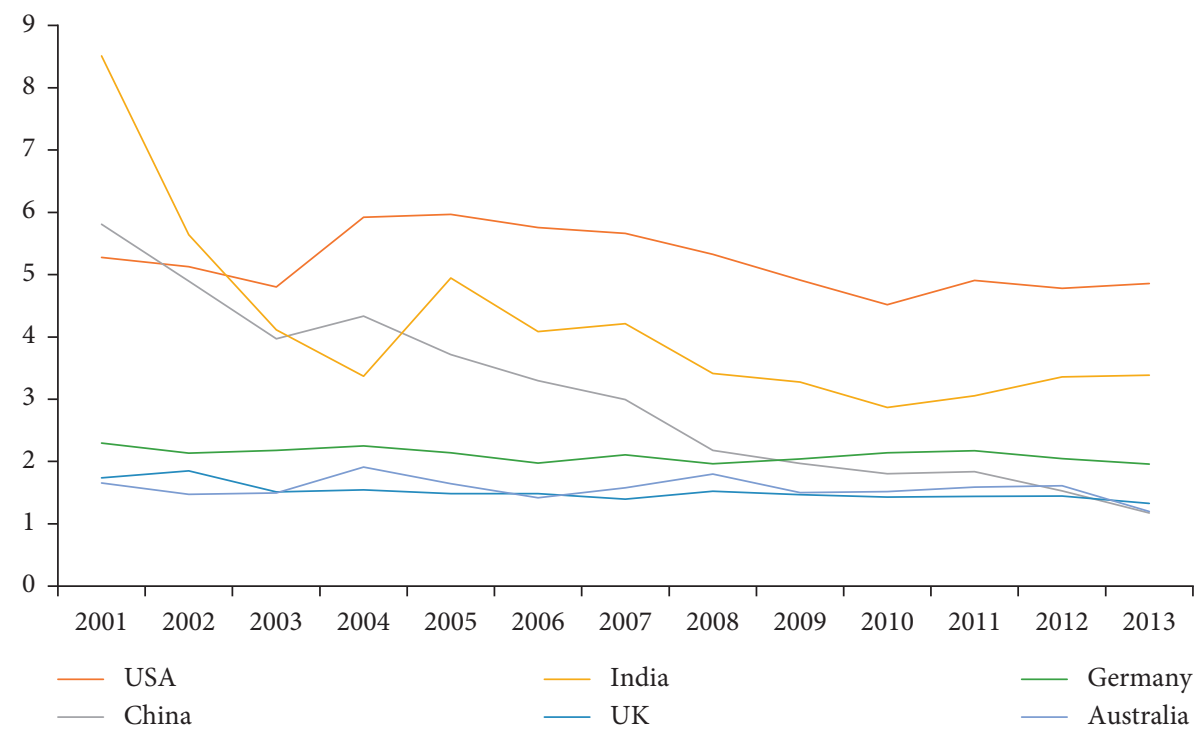

Figure 10: Time evolution of $f_{i}(k)$ for the six chosen countries.

\section{Conclusions}

In this paper, we investigated international scientific talent migration from 2001 to 2013 in the quantification. The data source is employed from patent applicants under the PCT. Next, international talent migration is abstracted as a kind of complex network with discrete dynamics for nodes, and the relationship between them is also discussed, so that the proposed analysis makes results more credible, and the unknown parameters of the discrete model are identified. A series of these quantitative topologies of international migration are established, and time evolution of international talent migration is given by calculating the values of some network indicators. In addition, with the help of hypothesis, the effectiveness of obstruct is discussed.

Based on the analysis, we maintain that the overall situation of international talent migration is relatively stable, but there exist some small fluctuations from 2001 to 2013. The USA has attracted a great number of talents from other countries. Emerging economies, such as China and India, have been from brain drain to brain gain. We also find that it becomes more convenient for scientific talents to immigrate to other countries. In addition, for host countries, obstructs of talents immigration is more and more weakened with the increasing number of residing talents. However, there exists a turning point, and, after the value, the effectiveness of obstruct is more negatively significant in the host countries.

The future work should focus on analysing the key determining factors affecting talent migration data, such GDP per capita, innovation, and R\&D expenditure. We will also attempt to study different types of migration of specific talents, such as young talents and top talents, and compare the migration laws for different types of talents. According to these analyses, some targeted policies could be offered to governments for attracting a great number of talents. In addition, there exist many advanced quantitative methods, which could be explicated to study talent migration, such as entropy-based measurement in [26], symmetry distribution in [27], and supervised text classification with a networked model in [28].

\section{Data Availability}

All data included in this article are available upon request to the corresponding author. There are no restrictions on data access. Also, the original data from Ref. [21] have been employed by many other works.

\section{Conflicts of Interest}

The authors declare that there are no conflicts of interest regarding the publication of this paper.

\section{Acknowledgments}

This work was supported by the Youth Program of President's Foundation of NAIS (no. 2020yzjj-019).

\section{References}

[1] R. B. Freeman, "Globalization of scientific and engineering talent: international mobility of students, workers, and ideas and the world economy," Economics of Innovation and New Technology, vol. 19, no. 5, pp. 393-406, 2010.

[2] P. Stephan, G. Scellato, and C. Franzoni, "International competition for PhDs and postdoctoral scholars: what does (and does not) matter," Innovation Policy and the Economy, vol. 15, no. 1, pp. 73-113, 2015.

[3] OECD, The Global Competition for Talent: Mobility of the Highly Skilled, OECD, Paris, France, 2008.

[4] S. Beechler and I. C. Woodward, "The global "war for talent"” Journal of International Management, vol. 15, no. 3, pp. 273-285, 2009.

[5] A. Solimano, "The international mobility of talent and its impact on global development," in Proceedings of the WIDER Discussion Paper, Santiago, Chile, August 2006. 
[6] A. Saxenian, "From brain drain to brain circulation: transnational communities and regional upgrading in India and China," Studies in Comparative International Development, vol. 40, no. 2, pp. 35-61, 2005.

[7] T. Straubhaar, "International Mobility of the Highly Skilled: Brain Gain, Brain Drain or Brain Exchange," in HWWA Discussion paper, vol. 88, Hamburg, Germany, 2000.

[8] S. P. Kerr, W. Kerr, Ç Ö rr., and C. Parsons, "Global talent flows," Journal of Economic Perspectives, vol. 30, no. 4, pp. 83-106, 2016.

[9] M. Czaika and S. Orazbayev, "The globalisation of scientific mobility, 1970-2014," Applied Geography, vol. 96, pp. 1-10, 2018.

[10] H. F. Moed and G. Halevi, "A bibliometric approach to tracking international scientific migration," Scientometrics, vol. 101, no. 3, pp. 1987-2001, 2014.

[11] E. Artuc, F. Docquier, Ç. Özden, and C. Parsons, "A global assessment of human capital mobility: the role of non-OECD destinations," World Development, vol. 65, pp. 6-26, 2015.

[12] Y. Wang, H. Luo, and Y. Shi, "Complex network analysis for international talent mobility based on bibliometrics," International Journal of Innovation Science, vol. 11, no. 3, pp. 419-435, 2019.

[13] Y. Wang, H. Luo, and Z. Li, "Network of global top scientific talent migration based on system identification," Systems Engineering-Theory \& Practice, vol. 39, no. 10, in Chinese, 2019.

[14] H. F. Moed, M'h. Aisati, and A. Plume, "Studying scientific migration in Scopus," Scientometrics, vol. 94, no. 3, pp. 929-942, 2013.

[15] A. Geuna, Ed., Global Mobility of Research Scientists: The Economics of Who Goes where and Why, Academic Press, Cambridge, MA, USA, 2015.

[16] K. Kim and J. E. Cohen, "Determinants of international migration flows to and from industrialized countries: a panel data approach beyond gravity," International Migration Review, vol. 44, no. 4, pp. 899-932, 2010.

[17] E. Tranos, M. Gheasi, and P. Nijkamp, "International migration: a global complex network," Environment and Planning B: Planning and Design, vol. 42, no. 1, pp. 4-22, 2015.

[18] G. Fagiolo and M. Mastrorillo, "International migration network: topology and modelling," Physical Review E, vol. 88, no. 1, Article ID 012812, 2013.

[19] S. Yang, X. Yang, C. Zhang et al., "Using social network theory for modelling human mobility," IEEE Network, vol. 24, no. 5, pp. 6-13, 2010.

[20] A. Nagurney, J. Pan, and L. Zhao, "Human migration networks with class transformations," Structure and Change in the Space Economy, pp. 239-258, Springer, Berlin, Heidelberg, 1993.

[21] E. Miguelez and C. Fink, "Measuring the international mobility of inventors: a new database," WIPO, vol. 8, 2013.

[22] C. Guan-Rong, W. Xiao-Fan, and L. Xiang, Introduction to Complex Networks: Models, Structures and Dynamics, Higher Education Press, Beijing, China, 2012.

[23] C. Godsil and G. F. Royle, Algebraic Graph Theory, Springer Science \& Business Media, Berlin, Germany, 2013.

[24] M. Beine, S. Bertoli, and J. Fernández-Huertas Moraga, “A practitioners' guide to gravity models of international migration," The World Economy, vol. 39, no. 4, pp. 496-512, 2016.

[25] K. Head and T. Mayer, "What separates us? sources of resistance to globalization," Canadian Journal of Economics/ Revue Canadienne D'économique, vol. 46, no. 4, pp. 11961231, 2013.
[26] J. Corrêa, A. Edilson, F. Silva et al., "Patterns of authors contribution in scientific manuscripts," Journal of Informetrics, vol. 11, no. 2, pp. 498-510, 2017.

[27] D. Amancio, F. Silva, L. Costa et al., "Concentric network symmetry grasps authors' styles in word adjacency networks," EPL (Europhysics Letters), vol. 110, no. 6, 2015.

[28] H. F. d. Arruda, L. d. F. Costa, and D. R. Amancio, "Using complex networks for text classification: discriminating informative and imaginative documents," EPL (Europhysics Letters), vol. 113, no. 2, 2016. 